\title{
Option contracts in fresh produce supply chain with circulation loss
}

\author{
Chong Wang ${ }^{1,2}$, Xu Chen ${ }^{1}$ \\ ${ }^{1}$ University of Electronic Science \& Technology of China, ${ }^{2}$ Sichuan Agricultural University (China) \\ w0000500@163.com, xchenxchen@,263.net
}

\section{Abstract:}

Purpose: The purpose of this paper is to investigate management decisions via option contracts in a two-stage supply chain in which a fresh produce supplier sells to a retailer, considering the circulation loss of the fresh produce.

Design/methodology/approach: Authors propose a Stackelberg model to analyze the supply chain members' decisions in the decentralized supply chain compared with the integrated one under the newsvendor framework.

Findings: The results illustrate that there exists a unique optimal option order quantity for the retailer and a unique optimal option order price for the supplier giving certain conditions; furthermore, option contracts cannot coordinate the fresh produce supply chain when the retailer only orders options.

Originality/value: Agricultural products especially fresh produce's characteristics such as circulation loss and high risk are considered. Option contracts and game theory are combined to manage the fresh produce supply chain's risk. The proposed tool and models are hoped to shed light to the future works in the field of supply chain risk management.

Keywords: fresh produce, supply chain, option contracts, management decisions 


\section{Introduction}

As the competition is intensified in today's market, many companies realize that the performance of their businesses highly depend on the collaboration and coordination across the supply chain. Unfortunately, the chain members are primarily concerned about their individual interests and that self serving focus often results in poor supply chain performance. Fresh produce's short life cycles result in little or no salvage value at the end of the selling season as well as amazing circulation loss both in quality and quantity, which makes supply chain coordination more critical. Fresh produce as a necessity of daily life plays an important role in the market. Therefore, it is urgent and important to apply supply chain's management theories and methods managing fresh produce's high risk.

Agricultural products supply chain management has generated significant interest lately. As a kind of perishable goods, fresh produce has received a great deal of attention especially. Lowe and Preckel (2004) points out that the supply chain in the food and agribusiness sector is characterized by long supply lead times combined with significant supply and demand uncertainties, and relatively thin margins. They review some of the literature on applications of decision technology tools for a selected set of agribusiness problems and conclude by outlining what they see as some of the significant new problems facing the industry. Ahumada and Villalobos $(2009,2011)$ review the main contributions in the field of production and distribution planning for agri-foods based on agricultural crops, present an operational model that generates short term planning decisions for the fresh produce industry. Banker and Mitra (2011) investigate the effects of digital trading platforms on commodity prices in agricultural supply chains by comparing transaction data on trading various grades of coffee from a recently implemented digital platform in India with similar transactions from a physical commodity auction held weekly and firm-gate prices in the coffee producing regions of India. Shen, Lai, Leung and Liang (2011) study the inventory replenishment model for perishable agricultural products in a simple two-level supply chain and demonstrate that the supply chain cost decreases with supplier and retailer's collaborative forecasting. However, the above literature do not combine the theory of risk management in the research of fresh produce supply chain.

The research of supply chain risk management involves the application of contracts and options. Lariviere and Porteus (2001) consider a simple supply-chain contract in which a manufacturer sells to a retailer facing a newsvendor problem and the lone contract parameter is a wholesale price. Cachon and Lariviere (2005) discuss revenues-sharing contracts. BarnesSchuster, Bassok and Anupindi (2002) analyze the role of options in a two-period correlated demand model. They show that channel coordination can be achieved only if the exercise price is piecewise linear and they develop sufficient conditions on the cost parameters so that linear prices coordinate the channel. Li, Ritchken and Wang (2009) investigate the role of forward 
commitments and option contracts in the presence of asymmetric information. They contrast the role of forward and option contracts and identify cases where combinations of the two are dominant. Zhao, Wang, Cheng, Yang and Huang (2010) take a cooperative game approach to consider the coordination issue using option contracts. They demonstrate that option contracts can coordinate the supply chain and achieve Pareto-improvement. Fu, Lee and Teo (2010) investigate the value of portfolio procurement in a supply chain, where a buyer can either procure parts for future demand from sellers using fixed price contracts or, option contracts or tap into the market for spot purchases. They derive the optimal portfolio procurement strategy for the buyer when both the demand and the spot price are random (either correlated or independent). Chen and Shen (2011) study a one-period two-party supply chain with a service requirement. They derive the retailer's optimal ordering policy and the supplier's optimal production policy in the presence of option contracts and a service requirement. However, the above studies do not consider agricultural products especially fresh produce and its characteristics. Considering the characteristics of fresh produce and using game theory, we combine option contracts with supply chain risk management to investigate the fresh produce supply chain management decisions.

The remainder of this paper is organized as follows. Problem description and assumptions are presented in section 2 . In section 3, we take the integrated supply chain as the base model. In sections 4, we focus on the retailer's and supplier's optimal ordering and pricing policies respectively. Fresh produce supply chain coordination is considered in section 5 . We conclude our findings in section 6 and highlight possible future work.

\section{Problem description and assumption}

We consider a two-stage supply chain in which the supplier is a Stackelberg leader selling a fresh produce to the retailer who is the follower. There is no opportunity for the retailer to replenish inventory once the selling season has begun. Thus, both the supplier and the retailer make decisions prior to the season. Before the beginning of the selling season, the retailer purchases options from the supplier at per unit price of $w$. Each option gives the retailer the right (not the obligation) to buy one unit of product at the exercise price of $\alpha w$ after demand has been observed. $\alpha$ is an exogenous parameter and $\alpha>0$. Then, the supplier decides the order and exercise prices according to the retailer's order quantity $Q$ and the stochastic market demand. The supplier delivers the products at per unit cost of $c$ and the retailer sells the product at per unit price of $p$ which is known.

Considering the features of fresh produce, we invite $\beta(0<\beta<1)$ to imply the circulation loss in quantity including the loss caused by nature or artificial factors such as load and unload, simple packing, extruding, and transportation et al. range from the initial ordering moment to the commodity arrive to the retailer. 
Let random variable $D$ be the demand which is non negative with a mean of $u$. Let $Q_{I}$ be the supply quantity in an integrated supply chain. The probability density function is $f(\cdot)$, cumulative distribution function is $F(\cdot)$. Let $F$ be differentiable, increasing and $f(0)=0$. Let $[x]^{+}=\max (0, x), \quad \bar{F}(\cdot)=1-F(\cdot)$.

We assume that the unsold fresh produce has no salvage value at the end of the selling season, and each of the shortages that do not meet demand incurs a unit shortage cost of $g$. To avoid trivialities, suppose $p>w+\alpha w>c$. The condition ensures profit for both parties. We also assume the chain members are risk neutral and information is symmetric. We start with the discussion of the base model i.e., the integrated supply chain.

\section{The integrated supply chain}

To begin, consider the integrated supply chain as the base model. This model is a useful benchmark. In the integrated supply chain, there is no intermediate links such as wholesale. The integrated supply chain's profit function, denoted $\pi_{I}\left(Q_{I}\right)$, is

$$
\pi_{I}\left(Q_{I}\right)=p \min \left[D, Q_{I}(1-\beta)\right]-c Q_{I}-g\left[D-Q_{I}(1-\beta)\right]^{+}
$$

The first term is the total sells revenue which is restricted to the total demand and the supply considering the circulation loss, and the second term is the supply cost. The last term is the shortage cost. Then the integrated supply chain's expected profit, denoted $E\left[\pi_{I}\left(Q_{I}\right)\right]$, is

$$
\left.E\left[\pi_{I}\left(Q_{I}\right)\right]=[(p+g)(1-\beta)-c] Q_{I}-(p+g)\right]_{0}^{Q_{I}(1-\beta)} F(x) d x-g u
$$

Proposition 1. In the integrated supply chain, there exists a unique optimal supply quantity $Q_{I}^{*}$ given by

$$
Q_{I}^{*}=\frac{1}{1-\beta} F^{-1}\left[1-\frac{c}{(p+g)(1-\beta)}\right]
$$

Proof. Because

$$
\begin{gathered}
d E\left[\pi_{I}\left(Q_{I}\right)\right] / d Q_{I}=[(p+g)(1-\beta)-c]-(p+g)(1-\beta) F\left[Q_{I}(1-\beta)\right] \\
d^{2} E\left[\pi_{I}\left(Q_{I}\right)\right] / d Q_{I}^{2}=-(p+g)(1-\beta)^{2} f\left[Q_{I}(1-\beta)\right]<0
\end{gathered}
$$

So, $E\left[\pi_{I}\left(Q_{I}\right)\right]$ is concave in $Q_{I}$, i.e., in the integrated supply chain, there exists a unique optimal $Q_{I}^{*}$ by solving Eq. (4) $=0$. The proof is complete. 


\section{The decentralized supply chain}

\subsection{The retailer's optimal ordering policy with option contracts}

Now we consider the retailer's optimal ordering policy with option contracts. The retailer now orders only options. The retailer's profit function, denoted $\pi_{R}(Q)$, is

$$
\pi_{R}(Q)=p \min [D, Q(1-\beta)]-\alpha w \min [D, Q(1-\beta)]-g[D-Q(1-\beta)]^{+}-w Q
$$

The first term is the total sells revenue which is restricted to the total demand and the ordered options considering the circulation loss, the second term is the options' exercise cost, and the third term is the shortage cost. The last term is the options' ordering cost. Then the retailer's expected profit, denoted $E\left[\pi_{R}(Q)\right]$, is

$$
E\left[\pi_{R}(Q)\right]=(p+g-\alpha w) \int_{0}^{Q(1-\beta)} \bar{F}(x) d x-w Q-g u
$$

Proposition 2. With option contracts in a fresh produce supply chain, there exists a unique optimal option order quantity $Q^{*}$ for the retailer given by

$$
Q^{*}=\frac{1}{1-\beta} F^{-1}\left[1-\frac{w}{(p+g-\alpha w)(1-\beta)}\right]
$$

Proof. Because

$$
\begin{aligned}
& d E\left[\pi_{R}(Q)\right] / d Q=(p+g-\alpha w)(1-\beta) \bar{F}[Q(1-\beta)]-w \\
& d^{2} E\left[\pi_{R}(Q)\right] / d Q^{2}=-(p+g-\alpha w)(1-\beta)^{2} f[Q(1-\beta)]<0
\end{aligned}
$$

So, $E\left[\pi_{R}(Q)\right]$, is concave in $Q$, i.e., there exists a unique optimal option order quantity $Q^{*}$ for the retailer by solving Eq. ( 8$)=0$. The proof is complete.

\subsection{The supplier's optimal pricing policy with option contracts}

After the fresh produce retailer announces $Q^{*}$, the supplier can decide the option order price $w$ and the option exercise price $\alpha w$. The supplier's profit function, denoted $\pi_{s}(w)$, is

$$
\pi_{S}(w)=w Q^{*}-c Q^{*}+\alpha w \min \left[D, Q^{*}(1-\beta)\right]
$$

The first term is the options' sells revenue, and the second term is the products' supply cost. The last term is the revenue when the options are exercised. Then the supplier's expected profit, denoted $E\left[\pi_{s}(W]\right)$, is

$$
E\left[\pi_{S}(w)\right]=(w-c) Q^{*}+\alpha w \int_{0}^{Q^{*}(1-\beta)} \bar{F}(x) d x
$$


Proposition 3. With option contracts in a fresh produce supply chain, when $w \geq c$, there exists a unique optimal option order price $w^{*}$ for the supplier given by

$$
w^{*}=\frac{c\left(1+\alpha(1-\beta) \bar{F}\left(Q^{*}(1-\beta)\right)\right)}{\left(1+\alpha(1-\beta) \bar{F}\left(Q^{*}(1-\beta)\right)\right)^{2}-\left(Q^{*}+\alpha \int_{0}^{Q^{*}(1-\beta)} \bar{F}(x) d x\right)(1-\beta) r\left(Q^{*}(1-\beta)\right)}
$$

And the optimal option exercise price is $\alpha w^{*}$, meanwhile $0<\alpha<p / w^{*}-1$.

Proof. Because

$$
\begin{aligned}
\frac{d E\left[\pi_{S}(w)\right]}{d w}= & Q^{*}+\alpha \int_{0}^{Q^{*}(1-\beta)} \bar{F}(x) d x+(w-c) \frac{d Q^{*}}{d w}+\alpha w(1-\beta) \bar{F}\left[Q^{*}(1-\beta)\right] \frac{d Q^{*}}{d w} \\
\frac{d^{2} E\left[\pi_{S}(w)\right]}{d w^{2}}= & 2\left\{1+\alpha(1-\beta) \bar{F}\left[Q^{*}(1-\beta)\right]\right\} \frac{d Q^{*}}{d w}-\alpha w(1-\beta)^{2} f\left[Q^{*}(1-\beta)\right]\left(\frac{d Q^{*}}{d w}\right)^{2} \\
& +\left\{w-c+\alpha w(1-\beta) \bar{F}\left[Q^{*}(1-\beta)\right]\right\} \frac{d^{2} Q^{*}}{d w^{2}}
\end{aligned}
$$

$$
d Q^{*} / d w=-(p+g) /\left(f\left(Q^{*}(1-\beta)\right)(p+g-\alpha w)^{2}(1-\beta)^{2}\right)
$$

Following Kouvelis and Zhao (2011), we define $r(\cdot)=f(\cdot) /(1-F(\cdot))$ as the hazard rate. Many distributions have a non-decreasing hazard rate. For example, uniform, normal, logistic, chisquared, and exponential distributions belong to this class of distributions (Bagnoli \& Bergstrom, 2005). From Eq. (7), $(p+g-\alpha w)(1-\beta)=w / \bar{F}\left(Q^{*}(1-\beta)\right)$, and take it into Eq. (14), we have

$$
\begin{gathered}
d Q^{*} / d w=-(p+g) \bar{F}\left(Q^{*}(1-\beta)\right) /\left(r\left(Q^{*}(1-\beta)\right) w^{2}\right) \\
\frac{d^{2} Q^{*}}{d w^{2}}=\frac{(p+g) f\left[Q^{*}(1-\beta)\right](1-\beta) \frac{d Q^{*}}{d w}}{r\left[Q^{*}(1-\beta)\right] w^{2}}+\frac{2(p+g) \bar{F}\left[Q^{*}(1-\beta)\right]}{r\left[Q^{*}(1-\beta)\right] w^{3}} \\
+\frac{(p+g) \bar{F}\left[Q^{*}(1-\beta)\right] \cdot r^{\prime}\left[Q^{*}(1-\beta)\right](1-\beta) \frac{d Q^{*}}{d w}}{r^{2}\left[Q^{*}(1-\beta)\right] w^{2}}
\end{gathered}
$$

Taking Eq. (15) and Eq. (16) into Eq. (13), we have 


$$
\begin{aligned}
\frac{d^{2} E\left[\pi_{S}(w)\right]}{d w^{2}}= & -\frac{2 \alpha(1-\beta)(p+g) \bar{F}\left[Q^{*}(1-\beta)\right]^{2}}{r\left[Q^{*}(1-\beta)\right] w^{2}} \\
& -\left(c+\alpha w(1-\beta) \bar{F}\left(Q^{*}(1-\beta)\right)\right) \frac{2(p+g) \bar{F}\left[Q^{*}(1-\beta)\right]}{r\left[Q^{*}(1-\beta)\right] w^{3}} \\
& -2 \alpha(1-\beta)^{2} \frac{(p+g)^{2} f\left[Q^{*}(1-\beta)\right] \bar{F}\left[Q^{*}(1-\beta)\right]^{2}}{r^{2}\left[Q^{*}(1-\beta)\right] w^{3}} \\
& -(w-c) \frac{(p+g)^{2} f\left[Q^{*}(1-\beta)\right](1-\beta) \bar{F}\left[Q^{*}(1-\beta)\right]}{r^{2}\left[Q^{*}(1-\beta)\right] w^{4}} \\
& -\alpha(1-\beta)^{2} \frac{(p+g)^{2} \bar{F}\left[Q^{*}(1-\beta)\right]^{3} r^{\prime}\left[Q^{*}(1-\beta)\right]}{r^{3}\left[Q^{*}(1-\beta)\right] w^{3}} \\
& -(w-c) \frac{(p+g)^{2} \bar{F}\left[Q^{*}(1-\beta)\right]^{2} r^{\prime}\left[Q^{*}(1-\beta)\right](1-\beta)}{r^{3}\left[Q^{*}(1-\beta)\right] w^{4}}
\end{aligned}
$$

From Eq. (17), when $w \geq c$, we can safely get $d^{2} E\left(\pi_{S}(w)\right) / d w^{2}<0$. So, when $w \geq c, E\left[\pi_{s}(w)\right]$, is concave in $w$, i.e., there exists a unique optimal option order price $w^{*}$ by taking Eq. (15) into Eq. (12) and solving Eq. (12) $=0$. Correspondingly, the optimal option exercise price is $\alpha w^{*}$. As $c<w^{*}+\alpha w^{*}<p$ and $\alpha>0$, so $0<\alpha<p / w^{*}-1$. The proof is complete.

Proposition 3 implies that, in order to avoid the market risk caused by demand uncertainty, the premise of the fresh producer willing to provide option contracts is that the option's order price be no low than the product's supply cost when the retailer only orders options.

\section{Fresh produce supply chain coordination with option contracts}

In the previous discussion, we give the base model and the chain parties' decisions with option contracts. We now are interested on whether option contracts can coordinate the fresh produce supply chain when the retailer only orders options.

Proposition 4. Option contracts cannot coordinate the fresh produce supply chain when the retailer only orders options.

Proof. As supply chain coordination requires that the decision of a decentralized chain is consist to an integrated chain. With proposition 1 and proposition 2 , let $Q^{*}=Q^{*}{ }_{I}$, we obtain

$$
\frac{1}{1-\beta} F^{-1}\left[1-\frac{c}{(p+g)(1-\beta)}\right]=\frac{1}{1-\beta} F^{-1}\left[1-\frac{w}{(p+g-\alpha w)(1-\beta)}\right]
$$

Thus, when the contracts parameters satisfy $w=c-\alpha c w /(p+g)<c$, option contracts can coordinate the fresh produce supply chain. But this condition is contrary to the condition which the supplier is willing to provide option contracts i.e., $w \geq c$ in proposition 3 . So option contracts cannot coordinate the fresh produce supply chain when the retailer only orders options. The proof is complete. 


\section{Conclusion and suggestions for further research}

In this paper, consider the characteristics of fresh produce and use the Stackelberg model, we investigate the role of option contracts and management decisions for the fresh produce supply chain. Meaningful conclusions are given as follows. 1) With option contracts in a fresh produce supply chain, there exists a unique optimal option order quantity for the retailer and a unique optimal option order price under certain conditions for the supplier. 2) Option contracts cannot coordinate the fresh produce supply chain when the retailer only orders options. This research can be extended to a case that the retailer orders both products and options to see whether option contracts can coordinate the fresh produce supply chain, furthermore extend it to multi-period settings.

\section{Acknowledgment}

The authors thank the editor and the referees for careful reading the paper. This research is partially supported by the National Natural Sciences Foundation of China (No. 71272128), Youth Foundation for Humanities and Social Sciences of Ministry of Education of China (No. 11YJC630022), the Fundamental Research Funds for the Central Universities (No. ZYGX2009X020) and Sichuan Province Key Technology R\&D Program (No. 2012FZ0003).

\section{References}

Ahumada, O., \& Villalobos, J.R. (2009). Application of planning models in the agri-food supply chain: A review. European Journal of Operational Research, 196(1), 1-20. http://dx.doi.org/10.1016/j.ejor.2008.02.014

Ahumada, O., \& Villalobos, J.R. (2011). Operational model for planning the harvest and distribution of perishable agricultural products. International Journal of Production Economics, 133(2), 677-687. http://dx.doi.org/10.1016/j.ijpe.2011.05.015

Bagnoli, M., \& Bergstrom, T.C. (2005). Log-concave probability and its applications. Economic Theory, 26, 445-469. http://dx.doi.org/10.1007/s00199-004-0514-4

Barnes-Schuster, D., Bassok, Y., \& Anupindi, R. (2002). Coordination and flexibility in supply contracts with options. Manufacturing \& Service Operations Management, 4(3), 171-207. http://dx.doi.org/10.1287/msom.4.3.171.7754

Banker, R., \& Mitra, S. (2011). The effects of digital trading platforms on commodity prices in agricultural supply chains. MIS Quarterly, 35(3), 599-611. 
Cachon, G.P., \& Lariviere, M.A. (2005). Supply chain coordination with revenue-sharing contracts: Strengths and limitations. Management Science, 51(1), 30-40. http://dx.doi.org/10.1287/mnsc.1040.0215

Chen, X., \& Shen, Z.J. (2012). An analysis on supply chain with options contracts and service requirement. IIE Transactions, 44(10), 805-819. http://dx.doi.org/10.1080/0740817X.2011.649383

Fu, Q., Lee, C.Y., \& Teo, C.P. (2010). Procurement management using option contracts: random spot price and the portfolio effect. IIE Transactions, 42(11), 793-811. http://dx.doi.org/10.1080/07408171003670983

Kouvelis, P., \& Zhao, W.H. (2011). The newsvendor problem and price-only contract when bankruptcy costs exist. Production and Operations Management, 20(6), 921-936. http://dx.doi.org/10.1111/j.1937-5956.2010.01211.x

Lariviere, M.A., \& Porteus, E.L. (2001). Selling to the newsvendor: An analysis of price-only contracts. Manufacture \& Service Operation Management, 3(4), 293-305. http://dx.doi.org/10.1287/msom.3.4.293.9971

Li, H.T., Ritchken, P., \& Wang, Y.Z. (2009). Option and forward contracting with asymmetric information: Valuation issues in supply chains. European Journal of Operational Research, 197(1), 134-148. http://dx.doi.org/10.1016/j.ejor.2008.06.021

Lowe, T.J., \& Preckel P.V. (2004). Decision technologies for agribusiness problems: A brief review of selected literature and a call for research. Manufacturing \& Service Operations Management, 6(3), 201-208. http://dx.doi.org/10.1287/msom.1040.0051

Shen, D.J., Lai K.K., Leung, S.C.H., \& Liang, L. (2011). Modelling and analysis of inventory replenishment for perishable agricultural products with buyer-seller collaboration. International Journal of Systems Science, 42(7), 1207-1217. http://dx.doi.org/10.1080/00207720903494643

Zhao, Y.X., Wang, S.Y., Cheng, T.C.E., Yang, X.Q., \& Huang, Z.M. (2010). Coordination of supply chains by option contracts: A cooperative game theory approach. European Journal of Operational Research, 207(1), 668-675. http://dx.doi.org/10.1016/j.ejor.2010.05.017

Journal of Industrial Engineering and Management, 2013 (www.jiem.org)

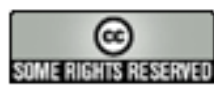

El artículo está con Reconocimiento-NoComercial 3.0 de Creative Commons. Puede copiarlo, distribuirlo y comunicarlo públicamente siempre que cite a su autor y a Intangible Capital. No lo utilice para fines comerciales. La licencia completa se puede consultar en http://creativecommons.org/licenses/by-nc/3.0/es/ 